BULLETIN Bulletin hispanique

HispaniQuE Université Michel de Montaigne Bordeaux

$116-2$ | 2014

Référentialité/autoréférentialité dans le roman espagnol contemporain : bilan et perspectives

\title{
Enésimo viaje a Eldorado del Teatro Guirigai
}

renovación del teatro callejero en una contrautopía colonial

Hernán Neira y Juan Manuel Fierro

\section{(2) OpenEdition}

Edición electrónica

URL: http://journals.openedition.org/bulletinhispanique/3599

DOI: 10.4000/bulletinhispanique.3599

ISBN: 979-10-300-0156-3

ISSN: 1775-3821

Editor

Presses universitaires de Bordeaux

Edición impresa

Fecha de publicación: 1 diciembre 2014

Paginación: 833-854

ISBN: 978-2-86781-963-6

ISSN: 0007-4640

Referencia electrónica

Hernán Neira y Juan Manuel Fierro, «Enésimo viaje a Eldorado de/ Teatro Guirigai », Bulletin hispanique [En línea], 116-2 | 2014, Publicado el 01 diciembre 2017, consultado el 02 mayo 2019. URL : http:// journals.openedition.org/bulletinhispanique/3599; DOI : 10.4000/bulletinhispanique.3599 


\title{
Enésimo viaje a Eldorado del Teatro Guirigai: renovación del teatro callejero en una contrautopía colonial ${ }^{1}$
}

\author{
Hernán Neira \\ Universidad de Santiago de Chile \\ con la colaboración de JuAn Manuel Fierro \\ Universidad de La Frontera, Chile
}

L’Énième voyage à Eldorado (1985), de la compagnie de théâtre espagnole Guirigai, peut être interprété à partir du rejet de la culture de la dictature franquiste, de la commémoration de 1492 et, surtout, des influences de la culture théatrale. Cette optique met en relief l'une des cuvres les plus originales de la dramaturgie espagnole des années 1980.

Mots-clés: Théâtre de rue, Guirigai, Énième voyage à Eldorado, Cinquième Centenaire.

Enésimo viaje a Eldorado (1985), del teatro Guirigai, puede ser interpretada a partir del descontento ante la cultura de la dictadura de Franco, de las efemérides del quinto centenario de 1492 y, sobre todo, desde influencias directamente originadas en el mundo de la cultura teatral, dando relieve a una de las obras más originales de la dramaturgia española de la década 1980.

Palabras claves: Teatro callejero, Teatro Guirigai, Enésimo viaje a Eldorado, Quinto Centenario.

Enésimo viaje a Eldorado (Umpteenth Journey to Eldorado, 1985) by the Spanish theater company Guirigai may be interpreted from the cultural discontent in relation to Franco's regime, from the perspective of the celebrations of the 5th centenary of 1492, and mainly from the theatrical culture. These perspectives bring out one of the most original plays of Spanish drama of the 1980's.

Keywords: Street theather, Guirigai Theater, Umpteenth journey to Eldorado, Fifth Centenary.

1. Fruto parcial del proyecto: La globalización como filosofía de la historia: bases americanas. Fondo Nacional de Investigación, Ciencia y Tecnología, Chile, no \#1085080.

Bulletin Hispanique, Tome 116, n 2 - décembre 2014 - p. 833-854. 
Zésimo viaje a Eldorado (en adelante Enésimo viaje...), obra de teatro callejero Agustín Iglesias ${ }^{2}$, puede ser interpretada a partir de una perspectiva doble. Por un lado, como expresión pública y libre del descontento ante la cultura oficial de la dictadura de Francisco Franco, que había concluido ocho ańos antes (1978), pero que todavía impregnaba las emociones y motivaciones de muchos artistas españoles. Por el otro, a partir de las efemérides del quinto centenario de 1492, que dieron lugar a múltiples actividades, con variadísimas tomas de posición, en el período 1982-1992. Sin embargo, estas dos perspectivas, aunque justificadas, son insuficientes, lo que nos obliga a analizar Enésimo viaje.... desde un tercer ángulo: en la obra se cruzan influencias directamente originadas en el mundo de la cultura dramático-teatral.

\section{LA OBRA}

La obra dispone de un guión, muy escueto, pero no de un texto que permita analizar parlamentos o párrafos que subsistan más allá de la representación. Para que nuestro análisis tenga sentido, es necesario describir una representación de la obra. Debido a que participa de lo efímero del teatro callejero y del happening, hay escasas huellas de sus presentaciones y una ausencia casi total de artículos eruditos o académicos sobre ella. Sin embargo, Enésimo viaje..., como muchas obras callejeras, consta de algunos invariantes o ejes conceptuales, que se adaptan al espacio, clima, espectadores y reacciones entre éstos y la obra. Cono todo, a diferencia de quienes analizan un texto escrito y «eterno" que a veces puede oponerse a su representación escénica «efímera», nosotros estamos obligados a centrarlos en lo efímero y la única huella completa que de ello queda es un registro videográfico de 1985 en Santiago de Compostela, más algunos recortes de prensa, algunas fotos conservadas con la compañía misma. La descripción de la representación de Santiago de Compostela ocupa aquí el lugar de lo que en los análisis del teatro clásico suele ser el estudio sobre el texto, de allí su extensión. Complementamos dicha información por una visita al galpón donde estaba radicada la compañía en 2004, en las afueras de Madrid, una larga entrevista personal con el director en esa misma oportunidad, sus respuestas por mail en 2011 y el guión. Sin embargo, la presentación en cada

2. Agustín Iglesias, 1953, Madrid. Director, actor y dramaturgo, fundador de la Compañía de Teatro GUIRIGAI (1979). Según el Directorio de la Asociación de Directores de Escena de España (ADE): «Ha desarrollado un lenguaje propio de Teatro de Calle, donde la dramaturgia va ligada al trabajo de máscaras, a la búsqueda de espacios no convencionales y al discurso musical. Dos claros ejemplos son Enésimo viaje a Eldorado (1986), espectáculo que aún sigue en repertorio y La fiesta de los locos (2001), cuya participación en los últimos festivales internacionales [...] le han consolidado internacionalmente». ADE cf. bibliografía. La compañía tuvo comienzos esforzados en Madrid. En la actualidad, con un prestigio sólido, posee una sala propia en Badajoz, España. Agradecimientos a Agustín Iglesias, director del Teatro Guirigai, por las facilidades y tiempo que nos dedicó. 
ciudad fue única. Eso obliga a concluir que el análisis del registro videográfico no puede ser considerado del mismo modo que lo sería en análisis de una representación en una sala de teatro, donde el desarrollo de la obra y la reacción del público son mucho más fijas.

Hechas estas consideraciones metodológicas, describamos la obra apoyándonos en el guión y en el ya mencionado montaje de Santiago de Compostela. La obra se articula sobre la base de un guión que define acciones (llamadas "pruebas») para cinco personajes principales (el conquistador, el sacerdote, la cortesana, la esposa y el mercader - Ilustración 1); dos músicos que están presentes toda la obra y dos personajes secundarios (el hombre en la mesa del banquete y el "pequeño burgués»). Los actores principales y los músicos recorren las calles de algunas ciudades previamente elegidas y en cuyo recorrido han sido instalados algunos elementos escenográficos, más bien mínimos pero imponentes estéticamente, que representan sobre todo las dificultades que encontraron algunos conquistadores europeos en tierras para ellos desconocidas. Actores y músicos se desplazan continuamente; sólo están fijos el hombre de la mesa del banquete y el pequeño burgués. Los espectadores -transeúntes, curiosos y asistentes motivados por la prensa- siguen o simplemente se encuentran con el paso de los actores. Representan, sin saberlo, a los indígenas, que también miraron, muchas veces con extrańeza u horror, a los invasores de sus ciudades y de sus campos, de forma que los espectadores son aquí parte de la obra misma y, la ciudad donde es representada, parte de la escenografía. Chema Fabero destaca «la perfecta adaptación que Guirigai consigue en el medio urbano donde trabajen $»^{3}$.

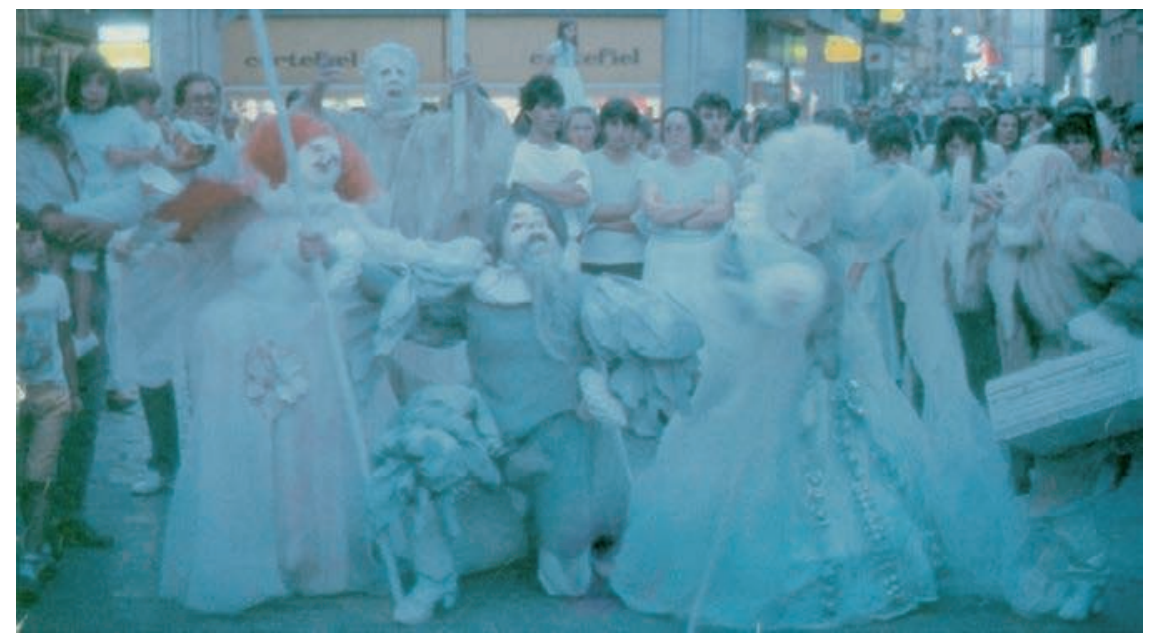

Ilustración 1. - La cortesana, el sacerdote, el conquistador, la dama, el mercader. Agustín Iglesias, directeur de la compagnie Guirigai @ Teatro Guirigai

3. Chema Fabero, Diario Lanza in Dossier de Prensa del Teatro Guirigai. Ciudad Real, España. 9 de septiembre 1987. 
La representación realizada en Santiago de Compostela duró 47 minutos, continuos, es decir, no hay ni descanso ni entreactos. Esa puesta en escena modificó parcialmente el orden del guión, que divide la obra en 13 «pruebas»o momentos estructurantes, aunque ni en ese y ni en los demás casos la alteración del orden implica eliminación de elementos. La compañía privilegió la función estructurante de estos elementos antes que la secuencia diacrónica, que puede ser alterada en varios aspectos sin que el efecto dramático y narrativo se pierda. Esta forma de organizar la obra manifiesta influencia del estructuralismo:

El espectáculo es un viaje, un viaje mágico, con la estructura de los cuentos populares. Y en todo viaje mágico hay un lugar para que los aventureros descansen y coman. Son los cuentos populares europeos y los poderes mágicos de los lugares extraños a explorar. Los trabajos del héroe que nos enseña Vladimir Propp ${ }^{4}$.

Participan en la «escena» cinco actores y dos músicos, quienes están siempre ante los ojos del público, sin descanso ni entreactos. La «escenografía» está constituida por el ambiente urbano y la incorporación en él de algunos elementos escenográficos a lo largo de lo que será el recorrido de los expedicionarios: cuerdas que simbolizan lianas, una cortina brillante que simboliza la penetración por el territorio y que será rasgada, pequeños petardos, bombas de humo y bengalas que simbolizan batallas, una máscara (¿isimboliza una calavera?) que será alzada por el conquistador y otros elementos menores. Su preparación se inicia con la visita a la ciudad, definición de las locaciones y la obtención de permisos por la ocupación de algunos lugares públicos. En el caso de la representación en Santiago de Compostela, en la plaza del Obradoiro son colocados unos lienzos sobre los cuales caminarán, como por puentes, el grupo de conquistadores, lienzos que penden desde un extremo del edificio de la sede episcopal y que dan a esas telas un aspecto aéreo y móvil. Desde los urinarios municipales, los expedicionarios atravesarán la zona antigua, llamada monumental, pasando por la plaza del Obradoiro, para concluir en el pórtico San Martín.

La obra comienza, para el público, en el momento en que el tambor aparece desde la salida de los urinarios públicos subterráneos de la ciudad, seguido por un segundo músico (trombón) y los cinco actores. Los actores llevan máscaras de muerto, que exageran grotesca y horriblemente los rasgos que imágenes idealizadas de los conquistadores en otras tradiciones históricas o dramáticas han trasmitido previamente. Las máscaras recuerdan rostros de la época llamada negra de Goya.

El tambor lleva un embudo en la parte superior de la cabeza, vuelto hacia abajo, como si fuera un sombrero, con penacho. Por su parte, el trombón lleva la cabeza descubierta. Ambos van vestidos de blanco, sin máscaras. El conquistador lleva una capa de una tela liviana y larga y, además, dos botas blancas, una corta y otra larga (la izquierda). La bota larga recuerda el retrato de Luis XIV pintado por Hyacinthe Rigaud, en 1701 donde el rey francés aparece mostrando una pierna cubierta con su culotte. En el caso del conquistador del Enésimo viaje..., la bota siempre visible ocupa el lugar de la pierna expuesta por

4. Mail de Agustín Iglesias al autor. 7 de julio 2011. 
Luis XIV. El conquistador lleva, además, una loriga, un morrión y una pica: su aspecto es agresivo, además de grotesco y ridículo.

Después de aparecer de los urinarios, los expedicionarios continúan por las calles antiguas y peatonales de Santiago de Compostela. El conquistador abre el camino, muchas veces amenazando con la pica a los indígenas (espectadores) que les observan. Esto corresponde al la letra c) del guión: "Contacto con los "indígenas" (el público). Relaciones de acercamiento y entrega de regalos»5. Acompaña al conquistador, a veces al lado, a veces detrás, la cortesana. Ésta viste un traje con guardainfante y deja al descubierto dos grandes pechos, postizos. Conviene destacar que el guardainfante es un pequeńo anacronismo, pues corresponde, no a mediados del siglo XVI, sino a mediados del siglo XVII. A esa pareja le siguen el sacerdote, que lleva una cruz casi como si fuera una pica, el mercader y otra mujer. La jerarquía de los personajes es clara en lo formal: a los 10:30 de iniciado el cortejo, el conquistador se arrodilla ante la cruz, pero en 24:30 se produce un forcejeo que opone la pica a la cruz, al parecer por cuál es la mejor ruta a seguir, lo que se resuelve cuando las mujeres toman un camino y los varones, perplejos, las siguen. Del mismo modo, en 27:00 las dos mujeres se oponen en una especie de desafío erótico que termina en golpes, siendo separadas por el conquistador, hechos que pueden ser interpretados como manifestación de las relaciones muchas veces conflictivas al interior de las expediciones.

El cortejo sigue avanzando por callejuelas que simbolizan una ruta de penetración en la selva, con lianas y escaramuzas con los indígenas, lo que corresponde, en el guión, a la tercera prueba: «El laberinto. En la persecución, la expedición se ve atrapada por un laberinto de lianas doradas que les agarra, obstaculizando la salida».

Los actores siguen caminando por las calles. Desembocan en la plaza del Arzobispado o del Obradoiro, donde, en los últimos metros, caminan por los lienzos blancos que han sido instalados con cables, de forma que los bordes están elevados y se mueven, como si fueran la balaustrada de un puente colgante. En el centro de la plaza se encuentra una mesa, ya puesta, y se sientan a comer, constituyendo una escena que destaca por su composición casi pictórica. Concluye el banquete (volveremos sobre él) y, a partir de entonces, el conquistador avanza como si estuviera cansado, con creciente dificultad, sin que, sin embargo, encuentre obstáculos especiales, lo que podemos imaginar simboliza el creciente agotamiento de los conquistadores a medida que se internaban en el continente americano. Finalmente, en el minuto 47:50, llegan a una escalinata, cubierta con una tela azul, que simboliza el océano, en cuyo fondo se ve una pequeña pirámide (situada en el Pórtico San Martín). Es la meta: El Dorado. Es el único momento cuyo orden diacrónico no podría ser modificado sin que se modifique el sentido de la obra misma. Los conquistadores suben la escalinata, se aproximan a la pirámide, la abren y adentro se encuentra

5. Agustín Iglesias, Enésimo viaje a Eldorado. Guión inédito, obra de teatro callejero. España, 1985. 
un hombre, sentado, que en el guión es descrito como un "pequeño burgués». Los conquistadores se asustan y se distancian unos pocos escalones. El hombre enciende un televisor (50:30) y los conquistadores se asustan y retiran todavía más, tapándose los oídos, como si del interior de la pirámide saliera un ruido enloquecedor (se escucha una música). Según el guión, intentan sacarse las cabezas. En 50:58 los conquistadores caen, el «pequeño burgués» al interior de la pirámide cierra la cortina y la obra concluye. El público que les ha seguido hasta allí o bien con el cual se han encontrado allí (unas ciento cincuenta o doscientas personas), aplaude. Los actores se quitan las máscaras y, junto con los músicos, hacen una reverencia al estilo del teatro clásico.

\section{CONTEXTO TEÓRICO, ORÍGENES Y SENTIDO DE LA OBRA}

Sobre la compañía Gurigai y, más aun, sobre Enésimo viaje..., no hemos encontrado artículos académicos. Eso plantea la dificultad de que no exista, propiamente, un estado del arte sobre nuestro tema específico, aunque sí existan referencias teóricas sobre la tradición del teatro callejero ${ }^{6}$.

No todo teatro callejero responde a un mismo objetivo ni tampoco puede ser comprendido desde el mismo contexto conceptual. Ahora bien, en el caso de Enésimo viaje, tanto por su coherencia con algunas teorías como por información que nos fue entregada por su mismo director, se puede identificar su filiación y propósito teórico con relativa claridad. Se trata de una obra de des-disciplinamiento, entendiendo por disciplinamiento una tecnología del cuerpo, que sitúa a éste en medio de relaciones de poder que lo «invierten» (linvestissent), lo marcan (le marquent), lo doman (le dressent), lo torturan (le supplicient) y lo fuerzan (l'astreignent) a trabajar (Foucault 34). El disciplinamiento modifica las fronteras externas con la finalidad de ampliar las internas. Enésimo viaje... desempeña justamente un papel contrario, es decir, la obra busca des-marcar y des-forzar al público y quizás a los actores mismos. La obra puede situarse en el marco del amplio propósito enunciado por Artaud ${ }^{7}$, quien concibe la intervención teatral como una "peste» al interior del ámbito ciudadano y burgués; ante la representación nadie debe quedar indiferente. Ello se consigue invirtiendo efectos y códigos teatrales convencionales:

El teatro actúa como la peste, porque afecta a importantes comunidades y las transforma en similar sentido. Posee el teatro, al igual que la peste, una cualidad que los hace a un tiempo victorioso y vengativo. Es fácil advertir que la catástrofe provocada por la peste en su andar es sólo enorme aniquilamiento. Un caos social, un desorden orgánico cargado de misterio, el desatarse impune de todo vicio, el exorcismo absoluto que persigue al alma llevándola a límites extremos, indican la presencia de un estado que, además, es una potencia última, a través de la cual se redescubre toda la fuerza inmensa de la naturaleza, toda vez que va a cumplirse algo esencial (p. 23).

6. La base de datos de artículos académicos Dialnet sólo informa de una entrevista hecha al director publicada en $A D E$ Teatro, número 126, 2009, bajo el título: Treinta años de Teatro Guirigai (1979-2009). ADE - Teatro, revista de la Asociación de Directores de Escena de España. La base de datos Scielo no entrega ningún artículo académico sobre la compañía.

7. Antonin Artaud, El Teatro y su doble. Retorica Ediciones. Argentina. 2002. 
Ese gran propósito se lleva a cabo por medio de una reinterpretación y transformación de los bululús y mojigangas, reinterpretadas en el ya mencionado sentido de teatro-peste de Artaud y, además, del «teatro pobre» de Jerzy Grotowsky. Grotowsky propuso un teatro basado en la relación directa entre la obra y la audiencia, prescindiendo de escenografía, vestuario e iluminación, lo que exigía centrarse en el movimiento del actor. Se exige al artista callejero privilegiar el trabajo corporal, gestual y también la utilización de los códigos multimodales ${ }^{8}$.

Si el actor, al plantarse públicamente como un desafío, desafía a otros y a través del exceso, la profanación y el sacrilegio injurioso se revela a sí mismo deshaciéndose de su máscara cotidiana, hace posible que el espectador lleve a cabo un proceso similar de autopenetración [...] Necesitamos un texto clásico al que podamos devolverle, mediante una especie de profanación, su verdad, o un texto moderno que aunque banal y estereotipado en su contenido pueda tener raíces profundas en la psique de la sociedad?.

Enésimo viaje... se origina como un espectáculo de intervención urbana, hecho por un encargo estatal que consistía en animar la entonces nueva estación de trenes de Chamartín, en Madrid. Los viajeros de una estación de tren se encuentran necesariamente en medio de otras ocupaciones y en un espacio, en principio, no destinado al teatro ni a espectáculos. Agustín Iglesias lo describe así: «El espectáculo surge de un encargo del llamado Centro Nacional de Nuevas Tendencias para animar y dramatizar espacios de la nueva estación de ferrocarril de Chamartín. Se nos da total libertad creativa ${ }^{10}$. Se trata de un encargo hecho por una institución muy específica, con fines también específicos. Vale la pena detenerse un momento en las características del Centro Nacional de Nuevas Tendencias Escénicas, que fue un organismo del Estado. Su misión (poco común en un organismo oficial) era ${ }^{11}$ :

El estudio, investigación y experimentación de las nuevas formas escénicas españolas, a través del montaje y puesta en escena de espectáculos y obras de nuevos autores y grupos teatrales [...] sólo se va a producir en este centro obras de autores españoles o producciones creadas por colectivos o grupos españoles. Es decir, obras vivas, contemporáneas -con texto o sin él-, pero que puedan situarse en una nueva sensibilidad ${ }^{12}$.

Ese propósito se vinculaba naturalmente con el teatro de vanguardia o trans vanguardia, pero al mismo tiempo se distanciaba de los grandes nombres internacionales que aplastaban al teatro joven español de los años $80^{13}$. Este

8. Una versión e interpretación latinoamericana de esas tendencias se encuentra en las Técnicas de Teatro Popular de Augusto Boal.

9. Jerzy Grotowski y Eugenio Barba, «El nuevo testamento del teatro» in Hacia un teatro pobre. Editorial Siglo XXI. 2004, p. 28.

10. Mail... op. cit., p. 3.

11. El Centro dejó de existir en 1995.

12. Guillermo Heras (dir.), «Centro Nacional de Nuevas Tendencias Escénicas» in El Público, Num. 4, cf. bibliografía.

13. El real decreto que lo crea en 1985 lo define así: «previa la aprobación de la Presidencia del 
teatro joven es parte de una contra cultura, nacionalista, pero ni conservadora, ni clásica, sino experimental, contraria al nacionalismo fascista promovido por el general Franco hasta su muerte en 1975. Por eso, aunque el propósito de «animar» la estación de Chamartín fuese limitado, no podía ser equivalente a una mera entretención, nada semejante a lo que vemos hoy en algunos recintos públicos en los que se coloca un aparato de televisión o música de fondo como supuesta entretención. La animación propuesta por Guirigai imponía exigencias intelectuales y emocionales a los viajeros y, para mantenerlos en esa exigencia, debía acudir a algunas técnicas del teatro callejero, como son la fanfarria, las máscaras, la exageración y, sobre todo, la originalidad que surge de la amalgama de lo anterior y de la creatividad del grupo. El diario madrileńo Ya comenta que, tomando en cuenta el poco interés del público madrileño por el teatro (sic), el Ministerio de Cultura ha aprovechado la «movida» con la finalidad de «convertir los andenes [de la estación de Charmatín], vestíbulos, terrazas y departamento de recogidas de equipajes [...] en improvisados escenarios teatrales móviles [...] Comediantes disfrazados con trajes multicolores, al son de una música estridente, escenifican acciones sin palabras» ${ }^{14}$. Recordemos que, desde comienzos de la década de 1980 hasta mediados de 1990, la movida fue un movimiento cultural inarticulado, pero coherente, muchas veces jocoso y desinhibido, de oposición a los remanentes de la cultura franquista, apoyado tácita u oficialmente por algunas autoridades socialistas, que reunió en Madrid a artistas, creadores y públicos en torno a expresiones nuevas y más desinhibidas que las de la década precedente.

Las propuestas de los entonces jóvenes integrantes de la compañía de Teatro Guirigai encajaban perfectamente con el objetivo del Centro Nacional de Nuevas Tendencias Escénicas, por una diversidad de motivos entre los que aquí hemos destacado algunos en las líneas precedentes. Ahora bien, la propuesta inicial, destinada a la animación de los andenes de Chamartín, aún no era la ocupación y recorrido de las calles de algunas ciudades, como lo será después, si bien los principales elementos del guión ya están presentes. En su desarrollo pleno, es decir, al presentarse en ciudades, Enésimo viaje a Eldorado re-visitaba críticamente el pasado colonial/imperial español; se mofaba sin discursos de la cultura franquista; era una obra contemporánea por su guión; sin palabras; española; realizada por un grupo joven; y con propuesta novedosa. Ello era posible, además, porque, a diferencia del público de un lugar de paso, como

Gobierno, este Ministerio [de Cultura] ha tenido a bien disponer: Artículo 1. Se crea el Centro Nacional de Nuevas Tendencias Escénicas (CNNTE) [...] En dicho Centro se programarán y realizarán los espectáculos dramáticos bajo la gerencia de aquel Organismo Autónomo, gozando para el logro de estos fines de plena autonomía artística y de creación. [...] El CNNTE, tendrá como misión el estudio, investigación y experimentación de las nuevas formas y tendencias escénicas españolas, a través de montaje y puesta en escena de obras de nuevos autores y colectivos teatrales [...] con especial atención a países y ámbitos geográficos de habla española». Boletín Oficial del Estado (BOE) no 219. [ en línea ]. 12 septiembre 1984 [ fecha de consulta: 13 de julio 2011].

14. Crónica Anónima. Diario Ya, 26 de abril 1985. 
es una estación, en una ciudad, más en días festivos y en verano, el público puede seguir una parte importante e incluso la totalidad del recorrido de los expedicionarios, lo que permite realizar una obra de mayor ambición.

El espectáculo fue ideado en 1985 y «estuvo en activo durante quince años y al ser en espacios y con públicos siempre diferentes obligaba a una continua inventiva colectiva ${ }^{15}$. Durante ese mismo período, se incrementaba el número y amplitud de actividades relativas a las conmemoraciones del quinto centenario de la llegada de los europeos a América. A principios de los años 1980, España había creado la Comisión Nacional para la Conmemoración del V Centenario del Descubrimiento de América, bajo la dependencia del Ministerio de Asuntos Exteriores. Esta comisión que fue modificada en 1991, por considerar que la fase preparatoria de las conmemoraciones ya había sido completada exitosamente (Boletín Oficial del Estado, Real Decreto 185, 3/8/91). Por medio de esa institución, el gobierno de España impulsó, financió y cofinanció muchas de aquellas conmemoraciones, dentro y fuera de las fronteras nacionales, obteniendo eco mayoritariamente favorable tanto en organismos internacionales como en las antiguas colonias americanas, lo que no impidió, por cierto, la existencia de muchas voces críticas, especialmente vinculadas a movimientos indígenas. Ahora bien, a medida que se aproximaba la fecha de 1992 y las voces críticas a la colonización española ganaban audiencia, la Comisión comprendió que el éxito de su propuesta requería un distanciamiento respecto de las formas tradicionales y especialmente franquistas de interpretar dicha colonización, y que dicha propuesta se enmarcaba en un plano más amplio de fortalecimiento de su política hacia las ex colonias, haciendo de la efeméride un «pretexto» que las transformaría «en un instrumento de cooperación entre Iberoamérica y España» ${ }^{16}$. Eso suponía, entre otras cosas, un acercamiento a las voces indigenistas "moderadas» y el reconocimiento de aspectos directamente negativos de la colonización. Luis Yáńez Barnuevo, que fue presidente de dicha comisión, lo expone así en un encuentro con comunidades indígenas que tuvo lugar en México:

La España plural y democrática no construye su modernidad hipertrofiando supuestos fastos pretéritos; por el contrario, asume que debe coadyuvar para que desaparezcan tanto las secuelas melancólicas del malogramiento amerindio como las no menos perniciosas ínfulas de unos malentendidos laureles celtibéricos ${ }^{17}$.

Enésimo viaje a Eldorado, creada sin vínculo ni financiero ni ideológico con la Comisión Nacional para la Conmemoración del V Centenario del Descubrimiento de América, es parte involuntaria de dicha abundancia y se sitúa en el grupo, amplio, de quienes abordaron la conmemoración desde un punto de vista crítico. En América, la perspectiva crítica en relación con el

15. Mail... op. cit., p. 5.

16. Luis Yáñez Barnuevo, Nótese que Yáñez utiliza el término «Iberoamérica». La Comisión Española depende del Instituto de Cooperación Iberoamericana.

17. Luis Yáńez Barnuevo, Encuentro de Teotitlán del Valle, folleto publicado por la Comisión Española. Madrid, España, 1990. 
pasado colonial español suele ser, al mismo tiempo, una perspectiva indigenista. A diferencia de ello, en Enésimo viaje..., las fuentes no son indigenistas, sino más bien europeas y de linajes múltiples, tan múltiple como lo fueron otras instituciones y autores que asumieron posturas críticas de las conmemoraciones de 1992. La abundancia y variedad de dichas actividades fueron parte del éxito que tuvo la iniciativa del gobierno de España y de otras instituciones gubernamentales o privadas. La obra re-significa la tradición y la interpretación del pasado colonial espańol, ofreciendo una nueva verdad sobre él, no porque oponga una nueva óptica, ni una óptica indigenista, sino más bien porque el carácter esperpéntico de los personajes y máscaras impide seguir confiando en ellos sin ofrecer nuevas alternativas, sin ofrecer un contradiscurso. Como plantea De Marinis,

Si la vida es un espectáculo de las apariencias, teatro engañoso, entonces el teatro -usado oportunamente- puede contribuir paradojalmente pero no demasiado, a ilusionar nuevamente la verdad que se oculta tras esas apariencias, para desenmascarar las mentiras cotidianas. Funcionando como una especie de «negación de la negación», las máscaras teatrales (las personae escénicas) deberían lograr derrumbar -según estas poéticas- aunque sólo fuera temporalmente, las máscaras cotidianas de los roles (de las personae cotidianas), detrás de las que el individuo (o de la comunidad de la cual forma parte ${ }^{18}$.

Durante la dictadura de Franco (1939-1975), que concluye con la constitución de 1978, el pasado colonial español fue convertido en exaltación del autoritarismo y del nacional-catolicismo, entendido como una cultura superior a las indígenas y también a otras vertientes de la cultura europea, sobre todo de origen liberal o socialista. Esa cultura franquista se manifestaba, entre otros muchos ámbitos, en las omisiones e inclusiones forzadas de los libros de filosofía y literatura de la enseñanza secundaria, cultura cuyos resabios aún persistirán más allá de 1978. En el libro de texto oficial de $6^{\circ}$ año de Bachillerato (último año de la enseñanza secundaria), publicado en 1975 y titulado Curso de literatura (española y universal), de un total de 380 páginas dedicadas a las literaturas española peninsular, europea y oriental (el exilio español casi no está representado), el conjunto de la literatura americana e hispano-americana ocupa 4 páginas $(1,05 \%)$, y no se mencionan las literaturas indígenas, aunque se dedican 13 líneas (de las cuales 6 con letra chica) a la literatura colonial «blanca». De la literatura mestiza sólo se nombra, sin agregar nada más, al Inca Garcilaso de la Vega (p. 221). Dentro de la «universalidad» que la ideología franquista quería dar al nacional-catolicismo, América era apenas un apéndice inferior y subordinado. En dicho libro de texto, además de otorgar primacía a la literatura europea y peninsular, se omiten los aspectos autocríticos de esa misma literatura, incluyendo la autocrítica realizada, ya en el siglo XVI, por autores como Bartolomé de las Casas y José de Acosta, quienes paradójicamente son españoles y católicos. El mencionado Curso de literatura, cuyo subtítulo es,

18. Marco De Marinis, Comprender el teatro. Lineamientos de una nueva teatrología, Editorial Galerna, 1997, p. 177. 
insisto: peninsular y universal, dedica 4 líneas a Las Casas, en el párrafo sobre los «Principales historiadores de Indias», y lo considera «iniciador de una campaña filantrópica y fanática que dio lugar a la leyenda negra que pesa sobre Espańa» (p. 157). Esa es la cultura y la omisión literaria en que se habían formado, al menos durante su adolescencia, muchos de los dramaturgos jóvenes. Contra ella reaccionarán muchos artistas de la nueva generación durante sus estudios universitarios y más aun cuando comiencen a ocupar un espacio en la escena teatral española de los años 1980. Tal es el caso de Agustín Iglesias, creador principal de la obra: «De ahí [del encargo del Centro Nacional de Nuevas Tendencias Escénicas] surge la idea de la expedición, la conquista, la broma y toda nuestra mala leche contra una lectura de valores patrios franquistas de la que estamos hartos» ${ }^{19}$.

En diversas oportunidades, la crítica a las conmemoraciones oficiales provenía de grupos indígenas residentes en países americanos o bien desde grupos simpatizantes de comunidades indígenas en Europa. En cambio, en la medida que fueron más permeables a la cultura protestante y después ilustrada y anticatólica, algunos países europeos, extra peninsulares, tuvieron mayor familiaridad que España con los textos críticos de la colonización generados en España misma, gracias a la divulgación europea de los textos de Las Casas, de Vitoria o de Acosta $^{20}$. La filosofía del progreso francesa (Condorcet, Comte) desacredita al colonialismo español, al que ve como una suerte de barbarie y despotismo que pronto será superada. Ello explica, en parte, el surgimiento en Francia de una obra como La Controverse de Valladolid, de Jean ClaudeCarrière (1992), que escenifica un encuentro entre Juan Ginés de Sepúlveda y Bartolomé de las Casas, en 1552, cuando el emperador Carlos V pide a la iglesia debatir y decidir, en favor o en contra de la humanidad de los indios (el debate histórico fue por escrito y no personalmente, como aparece en la obra francesa).

En la España de Franco, la omisión o minusvaloración de la tradición crítica e indigenista realizada por los programas oficiales de educación del período franquista influye en que la población no erudita tenga poca familiaridad con esa tradición que, aunque heterodoxa, también es hispánica. En España, incluso quienes deseaban distanciarse del nacional-catolicismo, no siempre tuvieron contacto con la crítica al imperialismo español producida en la misma España durante el siglo XVI. Por ello, la población anti franquista muchas veces tenía que acudir a tradiciones extra peninsulares o bien a creaciones propias para lograr el distanciamiento respecto del franquismo.

A diferencia de La controverse de Valladolid, Enésimo viaje... no es ni pretende ser una obra indigenista. Más bien, es una oportunidad para realizar

19. Mail... op. cit., p. 5.

20. España contaba, incluso durante el franquismo, con excelentes historiadores y filósofos que conocían los mencionados textos críticos españoles e hispanoamericanos, pero muchos estaban exiliados y, en la Península, faltaban ediciones y no habían llegado ámbitos más amplios de la cultura. 
una reflexión crítica sobre el pasado o el presente de los países que en 1492 iniciaron un amplio ciclo de aceleración de la ocupación europea del conjunto del planeta. Enésimo viaje... trabaja a partir de las capacidades autocríticas que subsistían en la misma cultura europea de los jóvenes que se distancian del nacional-catolicismo franquista. A partir de cierta orfandad en cuanto a estilo y tradición teatral, Enésimo viaje... asume la tradición autocrítica que proviene del teatro de lo grotesco peninsular y de las expresiones populares, todo lo cual es muy anterior al nacional-catolicismo, pero también asume creativamente una reacción a las circunstancias político-culturales de entonces: la «mala leche contra una lectura de valores patrios franquistas de la que estamos hartos».

Para ello, más que la crítica anti imperial y el indigenismo español del siglo XVI, Guirigai recupera una tradición hispánica que proviene del Arcipreste de Hita, de Cervantes, Quevedo, pero también de Rabelais, de los goliardos y de la tradición festiva europea (mail de Agustín Iglesias al autor). Con todo, no es fácil vincular la obra de forma ni directa ni unilateral a una tradición teatral española o extranjera; la obra tiene un sello propio, surgido en parte de las circunstancias y en parte de la inventiva de sus creadores y de su vínculo con cada ciudad. Agustín Iglesias reconoce también la influencia del arte póvera y del artista visual y dramaturgo Pistoletto. En muchos casos, el teatro callejero hace de la necesidad virtud, al darse posibilidades escénicas sin necesidad de arrendar una sala, pagar iluminación, tramoyas, impuestos y otros requerimientos que implican disponer de cantidades no menores de capital y liquidez financiera. Ahora bien, esto podría dar lugar simplemente a un arte pobre de recursos, pero el arte póvera es algo muy distinto. Inspirado y en parte iniciado por el artista italiano Michelangelo Pistoletto a mediados de los años 1960, el arte póvera introduce pluralidad en la tradicional uniformidad del estilo de cada obra o de cada artista. Es decir, acepta o incluso promueve que, en un mismo objeto artístico, el autor o autores introduzcan materiales, formas y estilos múltiples y que incluso en otras tradiciones serían considerados contradictorios e incompatibles. Aunque se inspire en algunos aspectos del ready made y la estética del objet trouvé, no se trata aquí de aislar un objeto que, puesto en un contexto artístico, llame la atención u obligue a reflexionar sobre lo cotidiano y el arte. En el arte póvera, los objetos cotidianos, a veces "pobres", pueden constituir la mayoría o totalidad de los materiales y, además, se entrega al espectador un papel activo, convirtiéndolo en parte de la obra misma, lo que puede ser vinculado con el happening. El diccionario on line del MoMa sostiene que el arte póvera:

Intentó romper la dicotomía entre el arte y la vida (Celant: Flash Art, 1967), principalmente por medio de la creación de happenings y esculturas hechas con materiales cotidianos. Tal actitud era opuesta al rol del arte meramente como reflejo de la realidad [...] Tanto como expresar su interés en temas sociales, los italianos [Pistoletto, Zorio, Paolini] estaban preocupados por varias formas de interacción física entre la obra de arte y su espectador ${ }^{21}$.

21. Museum of Modern Art, Art themes, cf. bibliografía (traducción libre). 
Efectivamente, en Enésimo viaje encontramos materiales de uso cotidiano a los que se les desvía la finalidad convencional, estilos de vestuario eclécticos, y también encontramos la participación del público por irrupción de la obra en el espacio urbano, de forma que la mirada que este arroja en los actores genera una extrañeza que es parte del sentido de la obra. Sin embargo, también hay influencias pictóricas, que mezclan imágenes renacentistas con otras surrealistas. Tal es el caso del banquete (35:40 a 38:40 en la versión de Santiago de Compostela - Ilustración 2). El guión lo describe en los siguientes términos:

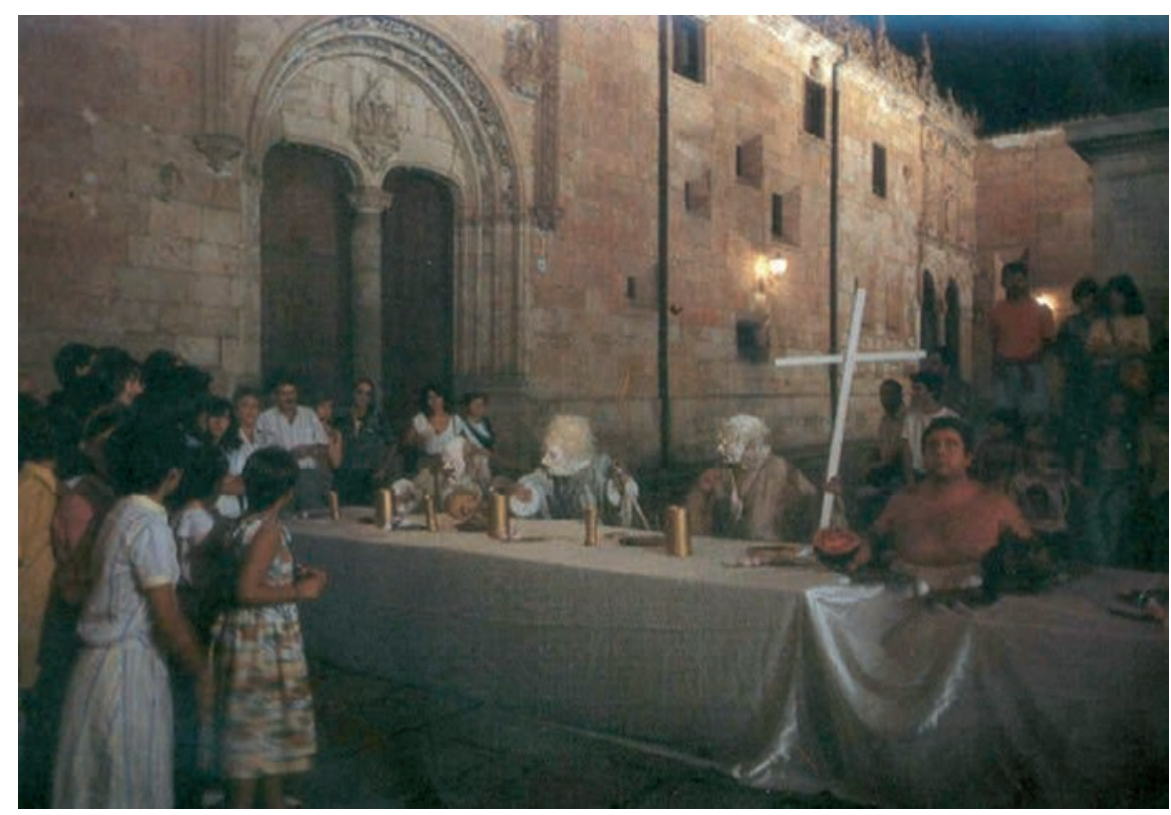

Ilustración 2. - El banquete. A la derecha, el hombre - cerdo. Agustín Iglesias, directeur de la compagnie Guirigai ( $)$ Teatro Guirigai

«Segunda prueba: La mesa del banquete. Una larguísima mesa cubierta con mantel blanco, llena de manjares y cubiertos de oro. Los personajes intentan apoderarse de las joyas. El mantel cobra vida y elevándose huye de ellos». En la representación de Santiago de Compostela, los expedicionarios se colocan en un lado, dando la espalda al edificio del obispado y dando la cara a los espectadores, como quien se coloca en la perspectiva del espectador ante la Última Cena de Leonardo da Vinci. Ahora bien, en un lado de la mesa se encuentra un hombre, como si fuera un cerdo listo para ser servido, del que sólo se ve la mitad superior del torso desnudo, quedando la otra mitad oculta bajo el mantel, como si el cuerpo estuviera cortado por la mitad. La imagen puede llevar a pensar en el canibalismo, pero también, por la disposición de los comensales, en los banquetes reales públicos, propios de algunas monarquías europeas en la época del absolutismo, o incluso puede llevar a pensar en el cuadro Lultima cena, tal como fue llevada a la tela por da Vinci. El aspecto 
surrealista de la escena se fortalece porque súbitamente el hombre-cerdo se levanta, camina y arrastra con su movimiento el mantel que ocultaba la parte inferior, haciendo caer los platos y cuanto se encuentra en la mesa (38:10). Con todo, Agustín Iglesias no da un significado determinado a la escena del banquete, a la que considera: «un fantástico gag propio de un cuento mágico. Por supuesto que las otras lecturas son válidas y algún católico se sintió ofendido. Pero la historia del arte es patrimonio de la humanidad, no solo de las religiones que pagaron al artista.. ${ }^{22}$

A pesar del contenido crítico de la obra, no se trata de teatro de tesis. La función anti disciplina está presente en todo el espectáculo, pero no como un discurso; ya hemos dicho que se trata, ante todo, de un espectáculo. La obra, más que oponer un discurso a otro, es más bien negativa, en el sentido de que genera distancia, crítica, un ser-visto-como-extraño, sin vehicular un mensaje afirmativo, ni siquiera antifranquista. Enésimo viaje..., por indagar en una cultura española más literaria que autocrítica del imperialismo y más libremente apropiada por los entonces jóvenes dramaturgos, sobrepasa los límites de la oposición al nacional-catolicismo franquista y le permite dialogar -sin haberlo buscado- con las polémicas efemérides ligadas al quinto centenario de la llegada de los europeos a América, efemérides que tuvieron lugar en muchos países del mundo. Asimismo, la obra, tal vez por el guión adaptable a las circunstancias, la composición de las imágenes que logra, la intensidad de las máscaras, lo grotesco del vestuario, la combinación de elementos cotidianos (el embudo ${ }^{23}$ en la cabeza del músico), la pica y la cruz de materiales casi precarios, las botas del conquistador que remedan una bota o una pierna real, casi impone la interacción con un público. Los espectadores, huyan o contemplen la pieza en la estación de trenes o en la calle, no quedan indiferentes. La obra transforma en algo grotesco e incluso macabro y repugnante a algunas figuras arquetípicas del momento en que la globalización se acelera vertiginosamente durante el siglo XVI y lo logra por la exageración de algunos de los aspectos más bajos de un episodio antes visto heroicamente. Del conquistador se destacan sus movimientos inarmónicos, sus botas desiguales y blancas (¡blancas!); de las mujeres, sus pechos y caderas deformes; $y$, del mercader, el cofre que jamás suelta.

La obra tiene algunos aspectos cínicos que subvierten los valores puestos en juego. Cínico en el sentido filosófico del término que da nombre a la escuela fundada por Diógenes de Sínope, es decir, que sustituye los aspectos elevados de la cultura por su antivalor, por la recuperación de los aspectos previamente entendidos como bajos y despreciables. Los actores no aparecen en la ciudad descendiendo de naves, ni llegan en caballos, sino que, en Santiago de Compostela, salen de los urinarios públicos, y, en Aurillac, llegan por el río Garona, en modestos, casi miserables botes a remo. Los actores -la expedición, la conquista, lo heroico- se ven siempre precarios en el paisaje urbano, que los

22. Mail... op. cit., p. 5.

23. N. de la R. Recuérdese el embudo invertido (símbolo de estupidez y locura) del falso doctor en el cuadro Extracción de la piedra de la locura de Jerónimo Bosco (Museo del Prado). 
aplasta con su eficacia, con su modernidad y con la circulación sin cuartel de transeúntes. Sin embargo, las figuras, trasmitidas como heroicas por la cultura franquista, y rechazadas por muchos jóvenes por su voluntad de distanciarse de esa cultura en los años 1970-1980, no pierden por ello atractivo sobre el autor del Enésimo viaje...

El personaje inspirador no es Lope de Aguirre, sino Hernán Cortés. Conocía muy bien las crónicas de Aguirre, estuvo escribiendo un texto sobre ese fascinante personaje, pero el texto inspirador fueron las cartas de Cortés sobre la entrada en la ciudad de Méjico. El asombro, la admiración y la codicia de los conquistadores son los motores de nuestros personajes. El asombro y el juego de la otra mirada ante el extrańo, que en este caso juega con la paradoja y la broma del conquistador conquistando a los suyos y viendo nuestra cultura con los ojos del extraño.

El autor produce deliberadamente una confusión en el público. Hernán Cortés no está asociado directamente a la búsqueda de El Dorado y representa, en el discurso sobre la conquista, la excelencia del ideal heroico; mientras que Lope de Aguirre, quien sí busca El Dorado, refleja la degradación y corrupción de dichos valores ${ }^{24}$. Ahora bien, Lope refleja seriamente la degradación de los valores de la conquista, sin pretensión de sarcasmo, al menos según lo que sabemos de él por las crónicas que han sido conservadas. Iglesias conoce el episodio de Lope de Aguirre por medio de la película Aguirre, der Zorn Gottes (Aguirre, cólera de Dios), de Werner Herzog, y, en consecuencia, conoce cuánto se presta dicho personaje para hacer una obra de cuestionamiento al imperialismo español y a la cultura nacional-católica. Sin embargo, se inspira en el más heroico y ejemplar de los personas de la conquista española: Hernán Cortés, un Hernán Cortés visto bajo la influencia irónica de la recién mencionada película de Herzog y, sobre todo, de esa «mala leche contra una lectura de valores patrios franquistas".

El enésimo viaje... da vida a un mito moribundo, el de conquista. Lo hace en 1985, desde una perspectiva distinta e incluso contraria a aquella que toma por razones político-diplomáticas, a fines de 1980, el gobierno de España. La obra y los representantes del gobierno contribuyen a la subsistencia del mito, incluso mediante su transformación. En el trabajo realizado por Guirigai, ya no interesa ni el contenido exacto de las anécdotas ni la cronología, porque el mito no se basa tanto en ellas, sino en aquellas estructuras que le dan sentido, en este caso, en una sola empresa de burla y sarcasmo.

Se produce, en consecuencia, una ambivalencia en la obra: esas figuras son y no son lo heroico, son y no son Espańa; son y no son la historia de la América española; son y no son una forma de ver, porque también son una forma de ser visto, un ser visto en la historia que es la propia y que es vista como algo grotesco, como una historia que es la propia, pero con la que ya no cabe la identificación, ni siquiera por la burla.

24. Beatriz Pastor, Discurso narrativo de la conquista de América, Editorial Casa de las Américas, La Habana, Cuba, 1983. 
La imaginería es fuerte, densa. Pero uno se acostumbra y, como, finalmente, sucede poca cosa, se termina por no saber verdaderamente por qué se sigue este cortejo barroco [...] Subsiste toda la panoplia simbólica de esta España llena de sangre, a vez grotesca y hierática, paradójica, extraña, y de la otra, que arroja una mirada sin piedad a la primera. Las dos están reunidas en una misma pasión ${ }^{25}$.

El desembarco, el recorrido, la espada, la cruz, la entrega de regalos a los indígenas, el botín, el conflicto entre los conquistadores, la rivalidad entre la iglesia y el poder civil, el banquete y la meta, en este caso, el descubrimiento de una pirámide: son momentos estructurantes de una crónica que narra, junto con el proceso de aceleración de la globalización, la confrontación de individuos más o menos aislados con un territorio inmenso al que pretenden dominar, dominio que se vuelve cada vez más difícil y menos creíble ${ }^{26}$. Cortés y Lope son sustituibles e intercambiables, lo heroico y lo vil, México y el Amazonas, la dama y la puta. Todos ellos son más bien figuras-funciones de una procesión que no en vano el periodista del diario La montagne denomina «barroco», con la salvedad que el término barroco también se usa cuando, por deficiencia o exceso de aquello sobre lo que se quiere hablar, no se encuentra la expresión justa. Una máscara que produce repulsión, mujeres cuyas formas redondas liquidan el erotismo: tal vez estamos ante el concepto kantiano de lo sublime, algo que no es hermoso y que sobrepasa el juicio estético por la imposibilidad de representarlo como una totalidad absoluta, como algo dado. De hecho, se trata de una procesión, de una continuidad dramática de una ceremonia, la de la Conquista, dada sobre la base del recorrido a lo largo de un escenario. El tiempo y el espacio no son aquí los de una obra de teatro, sino parte del «efecto» y parte de la comunicación con el público, todo lo cual tiene algo de auto de fe; también en éstos los condenados llevaban ropas que exaltaban grotescamente sus caracteres de condenados y eran vistos con sarcasmo y espanto por los espectadores que, sin embargo, asistían al espectáculo o lo contemplaban al pasar por las calles.

Los expedicionarios del Enésimo viaje... avanzan en medio del público -los indígenas-, ofreciéndoles el aspecto grotesco que les dan las máscaras macabras, los gestos inadecuados, los cuerpos deformes, las ropas acusadoras. Pero no sólo son máscaras grotescas, sino que son, al mismo tiempo, máscaras de muertos, cuyo efecto visual y estético es de tal amplitud e intensidad que las fotografías y el video, ya impresionantes, sólo dan un pequeño indicio de lo que fue un gran trabajo de Luis González Carreño ${ }^{27}$. Las máscaras contribuyen a atraer

25. «Crónica anónima», Diario La montagne, Clermont Ferrand, Francia. 24 de agosto 1990. Traducción libre.

26. Hernán Neira y al., Lope de Aguirre: elementos para la teoría del mito de la Conquista, Estudios Filológicos, n 41. Universidad Austral de Chile, Valdivia, Chile, 2006, p. 145-163.

27. Lás máscaras son obra de Luis González Carreño. En 2004, visitamos el galpón, entonces situado en un barrio industrial de Madrid, donde tenía sede la compañía. Allí conocimos el cuidadoso trabajo de dicho artista, aunque ya no estaban disponibles las máscaras del Enésimo viaje... Antonio de la Fuente Arjona dice de él en la revista Actores: «Luis González Carreño es 
la atención de los transeúntes y permiten visualizar el carácter de cada actor desde lejos. La presencia de la muerte en el rostro de los actores, vestidos como conquistadores, acentúa el anacronismo del episodio, otorgando a la conquista un aspecto escenográfico donde los valores más tradicionales de la conquista imperial española son invertidos y, a la vez, teatralizados, reproduciendo algunas de las ceremonias y episodios arquetípicos de la llegada de los primeros europeos a América. Los actores -viandantes de Santiago de Compostela o de otra ciudad- son muertos vivientes, «viajeros de otra cultura», sostiene Agustín Iglesias.

¿Pero no habíamos escuchado o leído que los españoles habían sido vistos como dioses por los indígenas en México y en Perú? ¿No dicen las crónicas -Cartas de relación de Cortés, La Araucana, de Ercilla- que los españoles eran admirados por los nativos? ¿ $\mathrm{O}$, contrariando esos documentos, los indígenas vieron a los europeos como algo grotesco, como una condena contra los que descendían de los barcos (y al mismo tiempo condena de aquellos que los veían llegar)? Visto por el indígena-espectador: ¿el morrión del conquistador equivale al capirote del condenado en al auto de fe? (No olvidemos que el embudo del músico lleva una cresta, como la de los morriones, donde se podían colocar plumas multicolores) ¿ $\mathrm{O}$ es lo grotesco una forma de verse a sí mismo, en la medida en que todo espańol es, también, heredero involuntario de una historia patria que desde el fin del franquismo debe ser reinterpretada para alejarse de los aspectos espantosos del nacional-catolicismo? ¿No eran grotescos los autos de fe? ¿Es, esa parte de la historia española, grotesca? ¿Cómo recuperar esa historia que se es y hacerlo de una forma liberadora, des-disciplinadora? Y, sobre todo: ¿cómo vio el público que presenció la obra en Santiago de Compostela a los actores? Esa es una ambivalencia característica que mantiene, en relación con la historia imperial y global que se acelera en 1492, la generación que da sus primeros pasos creativos al comienzo del pos franquismo y que, aunque le plantee conflictos, aborda dicha historia como algo propio: «También influye mi fascinación por las crónicas de la conquista que tiene la belleza de los descubrimientos de nuevos mundos y nuevas palabras. ${ }^{28}$

La obra, según recoge el video, tuvo éxito en la función de Santiago de Compostela: unas ciento cincuenta personas acompañan a los actores en el momento de encontrarse con la pirámide y aplauden con entusiasmo el fin de la representación -o de la performance; y fue representada en muchos otros lugares, también con éxito, según recogen los diarios. Eso da una idea de que esa des-identificación con la historia heroica por medio de personajes y actos grotescos o burlescos y ese verse como algo grotesco entra en comunicación con un público callejero- no estamos en una sala cerrada donde la ilustración del pública se mida, para comenzar, por el valor de la entrada, lo que implica

ante todo un creador de imágenes: ya sea realizando escenografías, vestuarios o máscaras para espectáculos ajenos, o alimentando sin parar su mundo singular y complejo». ACTORES, $\mathrm{n}^{\circ} 33$, Junio 1995. Madrid. Citado por Antonio de la Fuente Arjona mismo cf. bibliografía.

28. Mail... op. cit., p. 5. 
haber terminado la educación superior para disponer de un trabajo que permita pagarla. Es más, la obra entra en comunicación con un público superior al previsto. Recordemos que la obra tuvo, inicialmente, un objetivo limitado: animar y dramatizar espacios de la nueva estación de ferrocarril de Chamartín. Se nos da total libertad creativa. Esa "total libertad creativa» permite pasar de una animación de un espacio donde se busca atraer la atención de los transeúntes viajeros a la ocupación de una ciudad con un grupo que se desplaza en ella $y$, en ese desplazamiento, cuestiona la historia desde quienes son parte de ella, transeúntes-sedentarios, utilizando como instrumento lo grotesco y la ambigüedad, donde el público -los españoles- son los indígenas - ¿pero quiénes son esos expedicionarios? Esa pregunta no tiene exactamente respuesta; la obra no la da, ni pretende darla.

\section{La crítica. Finalidades y Contrafinalidades}

Hubo numerosos comentarios positivos en España y fuera de España que, en conjunto, destacan la calidad del espectáculo y la recuperación y vigencia del teatro callejero y su expresión mutimodal: música, mimo, circo, carnaval. Todo lo que contribuye a generar una genuina expresión artística, espectáculo a la vez dramático y social que de ningún modo se agota en su crítica o distanciamiento con el pasado colonial español.

Respecto de la presentación de 1985 en Santiago de Compostela, la redacción del Correo Gallego escribe ${ }^{29}$ :

[el grupo Guirigai] nos ofreció su particular aventura americana, con un Lope de Aguirre que surgía espectral de los urinarios de la Alameda (y de la memoria de Werner Herzog) seguido de un cortejo alucinado para atravesar la jungla compostelana hasta alcanzar Eldorado. Un espectáculo rebosante de sentido del humor, de sentido crítico y, sobre todo, de sentido plástico.

Naturalmente, un teatro que se presenta como deliberadamente provocador, tenía que provocar polémica (hubiera sido hasta decepcionante que no lo hiciera). En la España del recién inaugurado pos franquismo, la iglesia católica y los católicos tenían en los años 1980 una influencia cultural y política muy superior a la actual. En Jaén, la prensa señala, tal como nos fue confirmado por Agustín Iglesias, que hubo quejas ante la policía y ante el alcalde, por considerar que se ofendía a la religión católica. El episodio que concentró la polémica fue el remedo de misa de acción de gracias (minutos 11:40 a 14:50 en la versión de Santiago de Compostela), en la cual el sacerdote, que también lleva una máscara macabra, realiza una eucaristía. Aunque no hubo violencia física, sí hubo amenazas e insultos a las autoridades municipales y a los responsables del área de cultura ${ }^{30}$. 
Tras la presentación en España, vinieron las presentaciones en el extranjero, especialmente en festivales (las que permitieron la financiación de la obra). La crítica favorable continúa dos años después. El diario Jornal de noticias, de Porto, escribe:

«Enésimo viaje a Eldorado» representada por una de las compañías más representativas del nuevo teatro castellano, Guirigai, de Madrid, constituyó el «prólogo» de la $10^{\circ}$ edición del Festival Internacional de Teatro de Expresión Ibérica-FITEI [...] Por el impacto y fuera de lo común del espectáculo (y también por su alta calidad), puede decirse que la actuación de Guirigai fue una llave de oro para el FITEI ${ }^{31}$.

Una semana más tarde de haberse presentado en Porto, la compañía parte a Lyon, de lo que da cuenta J-Ph. Mestre en el diario Le progrès ${ }^{32}$ :

Los miembros del Colectivo Guirigai restituyen las oraciones de la multitud, la desmesura de los continentes, el humo de las batallas. Nos hacen encontrar el teatro de calle, convidándonos a seguirle los talones, a reírnos y a bailar con ellos, a divertirnos con la enormidad de sus provocaciones [...] Pero Eldorado es sólo un espejo que nos es puesto delante, y la locura de la utopía de los conquistadores desemboca sobre la plácida realidad de un burgués madrileño.

La obra superó su limitado objetivo inicial y circuló exitosamente en distintas ciudades y fuera de las fronteras españolas. Estuvo en Nueva York, Oporto, Lyon, Caracas y otras ciudades, adaptando el guión a las características locales. En Caracas tuvo el privilegio de cerrar el Festival Internacional de Teatro de Venezuela, en 1995, ante aproximadamente 20.000 espectadores, agregando una escena donde los expedicionarios realizan una suerte de desafío con los músicos del grupo venezolano Madera.

En 1988 la obra se presentó en el Lincoln Center, Nueva York. La productora del centro describió la obra en los siguientes términos ${ }^{33}$ :

La actuación de Guirigai superó a cualquier otro teatro de calle que yo haya visto en Estados Unidos. Un espectáculo enormemente visual, no verbal, que se hace inmediatamente comprensible para la audiencia americana. El público, más de 3.000 personas, se movió completamente fascinado por el itinerario del Lincoln Center, participando en la aventura y disfrutando de la reflexión sobre la vida urbana [...] No hubo un momento de la representación que no fuera excelente teatro.

Enésimo viaje a Eldorado superó con mucho las ambiciones más bien limitadas, aunque importantes desde el punto de vista de la renovación dramático-teatral, originadas por el encargo del Centro Nacional de Nuevas Tendencias Escénicas. Dicha superación fue fruto de una combinación de causas propiamente estéticas y creativas de la compañía con otras que le son externas y que no podía controlar, como fueron las efemérides del Quinto Centenario, que culminaron en 1992. Estas, aunque también restringidas, ya en la década de 1980 incrementaron la discusión sobre el pasado español e incrementaron, también, la receptividad hacia las visiones críticas de la época de la conquista

31. Crónica anónima, 2 de junio 1987. Traducción libre.

32. 7 de junio 1987. Traducción libre.

33. Carta de Jeneneth S. Webster a Antonia Bueno, 10 de agosto 1988. 
de América. En conjunto, Enésimo viaje cumple con la finalidad de renovación teatral a partir de cierta orfandad de tradiciones y de la obligación, justamente por ella, de buscar referentes en tradiciones aparentemente más lejanas en el tiempo y en el espacio. No es extraño, porque en materia cultural la distancia temporal o geográfica puede ser convertida en motivo de cercanía y materia de reelaboración estética. Tal es el caso de Enésimo viaje..., en especial por lograr un diálogo entre, por un lado, corrientes tradicionales del teatro callejero europeo y, por otro, algunas corrientes más actuales, como el teatro antropológico de Barba y el teatro pobre de Grotowsky, respectivamente, y en particular con el arte póvera, expresión contemporánea que permite un reencuentro que no consiste en buscar la imitación de lo que, en otro contexto, tal vez fue, sino en mirar la tradición para recrearla.

Lo mismo puede decirse del mito de Lope de Aguirre y de El Dorado, que se entremezcla aquí con el mito de la Conquista y con el de Cortés. Guirigai les da vida transformándolos, poniéndolos en un escenario ecléctico y donde el público ve los personajes con la extrañeza con que, tal vez, fueron vistos el mismo Cortés y el mismo Aguirre por los indígenas. El anacronismo de la aparición de los expedicionarios en las calles permite renovar ese mito, invirtiendo algunas de sus características y, en especial, la capacidad de matar de los conquistadores, que se vuelve contra ellos mismos por medio de las máscaras macabras. Son muertos vivientes, ellos son la muerte, ante los ojos de los espectadores-indígenas de hoy, quizás de ellos mismos y de los espectadores de entonces. De esa mirada y de ese ser visto también nació la América de hoy. 


\section{Bibliografía}

Artaud Antonin, El Teatro y su doble, Retorica Ediciones, Buenos Aires, Argentina, 2002

Asociación de Directores de Escena de España. Directorio [En línea] Entrada Agustín Iglesias. [fecha de consulta: 12 de julio 2011]: Disponible en: http://webcache. googleusercontent.com/search?q=cache:fZ1FHyralkwJ:www.adeteatro.com/detalle_socio. php\%3Fid_socio $=144+»$ teatro+guirigai $» \& c d=64 \&$ hl $=$ es $\& c t=c l n k \& l r=l a n g \_p t \mid l a n g$

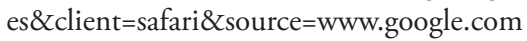

Boal Augusto, Técnicas latinoamericanas de teatro popular, Editorial Nueva Imagen, México. 1982.

Boletín Oficial del Estado [En línea]. Gobierno de España [ fecha de consulta: 6 de julio 2011]. Disponible en:

http://www.boe.es/aeboe/consultas/bases_datos/doc.php?coleccion=iberlex\&id=19 91/19827\&codmap=

Carrière Jean-Claude, La controverse de Valladolid, Belfond, Le Pré aux Clercs, 1992. (ISBN 2-7144-2879-7).

Chema Fabero, Diario Lanza. Ciudad Real, España. 9 de septiembre 1987.

Correa-Lázaro, Curso de literatura (española y universal). 6º Curso. Anaya, Madrid, España. 1975.

De la Fuente Arjona Antonio, ACTORES, no 33 [En línea]. Junio 1995. [fecha de consulta: 1 de julio 2011]. Disponible en: http://delafuentearjona.viadomus.com/content/view/212/90/

De Marinis Marco, Comprender el teatro. Lineamientos de una nueva teatrología. Editorial Galerna. 1997.

Diario Ideal. Jaén, España. 25 de mayo 1986.

Diario Jornal de noticias, Porto. 2 de junio 1987.

Diario La montagne, Clermont Ferrand, Francia. 24 de agosto 1990.

Diario Ya. Madrid, España. 26 de abril 1985.

Foucault Michel, Surveiller et punir, naissance de la prison, Gallimard, collection TEL. París, Francia. 2003.

Grotowski Jerzy, y Barba Eugenio, «El nuevo testamento del teatro» in Hacia un teatro pobre, Editorial Siglo XXI. 2004.

Heras Guillermo (dir.), «Centro Nacional de Nuevas Tendencias Escénicas» in El Público, Num. 4, Archivo Virtual Artes Escénicas. [En línea]. 1984 [ fecha de consulta: 10 de julio 2011]. Disponible en:

http://artesescenicas.uclm.es/index.php?sec=conte\&id=24

Iglesias Agustín, Mail al autor, 7 julio 2011. Inédito.

Iglesias Agustín, Enésimo viaje a Eldorado, Guión Inédito, obra de teatro callejero. España, 1985.

Mestre J-Ph., Diario Le progrès, Lyon, Francia, 7 de junio 1987.

Museum of Modern Art. Art themes. [En línea]. Grove Art On Line. Oxford University Press. Nueva York. [fecha de consulta: 9 de julio 201]. Disponible en: www.moma. org/collection/theme.php?theme_id=10454 
Neira Hernán y al., Lope de Aguirre: elementos para la teoría del mito de la Conquista, Estudios Filológicos, $\mathrm{n}^{\circ}$ 41. Universidad Austral de Chile. Valdivia, Chile, 2006. pp. 145-163.

Pastor Beatriz, Discurso narrativo de la conquista de América. Editorial Casa de las Américas, La Habana, Cuba, 1983.

Teatro Guirigai, Archivo privado de la compañía, Los Santos de Maimona. España.

Teatro Guirigai, Guión de Enésimo viaje a Eldorado, Inédito, s/f. España.

Yañez Barnuevo Luis, Encuentro de Teotitlán del Valle, folleto publicado por la Comisión Española, Madrid, España, 1990.

Webster Jeneneth S. Correspondencia inédita con Antonia Bueno. 